\title{
ENTREVista COM DAVi ArrigucCi JR. ${ }^{490}$
}

Todo o meu trabalho nos estudos literários - de crítico, ensaísta e professor de teoria literária da USP - sempre esteve relacionado com a teoria e a prática da interpretação. Em 1990, quando defendi a tese de livre-docência com um livro sobre Manuel Bandeira, tive de formular, numa das provas, o projeto de um curso. Pensei, então, um curso sobre métodos e técnicas de análise e interpretação da obra literária, o que acabou sendo um pouco o resumo de minha trajetória, do aprendizado desde os contatos iniciais que tive na universidade com a prática da análise de textos. Toda a crítica que desenvolvi nos meus ensaios e nas aulas está fundada num tipo de leitura cerrada, de close reading, que não é exatamente o close reading de tendência norte-americana dos anos de 1940, 1950 e 1960, apesar de ter bebido nisso também, mas um close reading muito assentado na estilística, que é uma espécie de fenomenologia com psicanálise e crítica social, e num modo específico de abordar os textos que aprendi com meus mestres da crítica brasileira. A vertente da estilística que mais me interessou primeiro foi a da estilística espanhola de Dámaso Alonso, voltada sobretudo para a leitura do texto poético, e, em seguida, a alemã, representada por Leo Spitzer e Erich Auerbach, grandes críticos, extraordinários leitores de literatura. Além disso, é claro, estava acompanhando, fazia muito tempo, as obras de críticos daqui, como Mário de Andrade, Augusto Meyer, Otto Maria Carpeaux (que já era nosso) e, sobretudo, Antonio Candido.

O terreno da interpretação é vasto. Você falou um pouco da sua experiência na análise de textos. Na sua formação, a interpretação em outras áreas teve um peso decisivo?

O terreno da interpretação é de fato muito vasto e bastante complexo, mas talvez seja o momento de tentarmos definir alguns pontos fundamentais.

A teoria da interpretação é tão complexa e extensa que vai além das minhas forças, restritas ao terreno literário propriamente dito. Não tenho uma formação tão ampla e poderosa para responder em todos os campos em que a interpretação tem um papel decisivo: basta imaginarmos o campo imenso da exegese bíblica, a que muitas vezes devemos voltar em nosso trabalho, mas é sempre um enorme desafio. Existe uma hermenêutica filosófica, muito importante, e que eu estudei um pouco. Li vários livros nesta direção, alguns deles pesaram bastante na minha formação, como os de Gadamer e de Luigi Pareyson, sem falar em Schleiermacher e a questão do círculo hermenêutico. Há a hermenêutica psicanalítica e sua discussão, como a de Paul Ricoeur, por quem também me interessei vivamente. Mas foi na prática da análise de textos literários que nasceu a minha inquietação teórica com relação à interpretação.

\section{Talvez seja o momento de detalhar os métodos da interpretação na literatura.}

Quando eu falo em interpretação na literatura, penso na expressão verbal da compreensão, na tradução em linguagem daquilo que compreendo no modo de ser de uma obra literária. Existem duas atitudes básicas nos estudos literários: a atitude de explicação e a de compreensão. Explicação significa tomar a estrutura significativa da obra com relação a estruturas maiores. Ou seja, toma-se aquele texto particular, aquele conjunto de signos particulares que o constituem e o inserimos em contextos mais amplos, seja na dimensão da história seja na da linguagem seja ainda na da cultura em geral, aproximando-nos da esfera de disciplinas afins. A atitude explicativa traduz aquele conjunto de signos e seus problemas

\footnotetext{
${ }^{490}$ Publicado originalmente na Revista Brasileira de Psicanálise, v. 39, n. 1, 2005.
} 
numa outra coisa. Essa atitude pode ser muito importante na tarefa de abordagem dos textos, mas ela não é a tarefa decisiva para o intérprete da literatura; constitui apenas um preâmbulo para o trabalho interno mais importante. A tarefa decisiva é a tarefa de compreensão. E a compreensão consiste justamente na penetração na estrutura significativa da obra.

Como você disse, a atitude explicativa é fundamental, mas não decisiva. É possível falar em limites da explicação?

Até onde explicar para compreender? T. S. Eliot, em vários ensaios do começo do século XX, sobre a função e as fronteiras da crítica, tratou dessa questão tão importante para a geração dele. Segundo Eliot, o poema deve ser compreendido em si mesmo e por si mesmo. A poesia é capaz de nos dar uma coisa que só ela dá. Nenhuma explicação, nenhuma tradução do poema em outra coisa poderá responder à pergunta que o poema nos coloca, a pergunta drummondiana: "trouxeste a chave?". Mas nós não podemos compreender sem explicar. Há obras literárias que exigem, necessariamente, a explicação, ou seja, a elucidação de todos aqueles elementos objetivos do texto que emperram ou dificultam a compreensão.

\section{A explicação pode ser uma espécie de superação inicial de alguns dos obstáculos do} texto.

O poema que requer uma explicação é um poema afastado de nós por uma ou por várias das razões do seu modo de ser. Ou seja, por exemplo: por uma linguagem peculiar. A linguagem pode ser arcaica, pode conter alusões difíceis de decifrar. Ela também pode ser de tal modo singularizada pelo uso estilístico que dela faz o autor, que se torna difícil, como é o caso de Guimarães Rosa, entre nós, ou o de Louis-Ferdinand Céline, na literatura francesa.

Há, então, uma dificuldade a ser enfrentada pela explicação inicial. A operação explicativa daquilo que emperra a compreensão é o comentário. O comentário é algo velhíssimo e surgiu pela primeira vez, na história do Ocidente, quando os textos de Homero, no século III a.C., começaram a ficar difíceis para quem os escutava ou no seu processo de transmissão. O século VIII a.C. é o século de Homero, e nesse intervalo até o III muita coisa se interpunha entre o receptor e o texto para que ele o pudesse entender. Então, houve a necessidade de uma disciplina para explicar os textos difíceis de Homero, e assim surgiu a filologia. Pode-se dizer que a explicação necessária com que se deve trabalhar diante dos textos cujo acesso se torna difícil é o comentário filológico. O comentário é um comentário factual dos elementos objetivos e depende, sobretudo, do conhecimento da história e da linguagem.

O comentário filológico foi mudando ao longo dos séculos. E o que se pode perceber é que ele virou uma espécie de marginália nos textos literários ao longo da história da literatura. E foi tão importante que às vezes se intrometeu dentro dos textos. Há obras que contêm o seu próprio comentário ou poetas que comentam os seus próprios poemas, como foi, por exemplo, o caso de Eliot, já citado, ou de Umberto Saba, na Itália, autor de um longo comentário que acompanha o El canzoniere. O itinerário de Paságarda, de Manuel Bandeira, tão notável pela qualidade da prosa com que enlaça poesia e experiência vivida, pode ser lido nesse sentido.

Talvez seja interessante ressaltar as armadilhas colocadas no meio do caminho da interpretação. $O$ processo interpretativo pode ficar totalmente comprometido por conta de um equívoco no início da leitura, não é verdade?

Deve-se resolver, antes de mais nada, o problema da tradução literal dos significados expressos. Isso pode parecer simples e fácil, resumindo-se ao emprego do dicionário, mas nem sempre o é. É uma operação crítica de primeira grandeza, envolvendo paciência, 
erudição e senso crítico, além de antenas propícias. Eu posso interpretar mal uma palavra do texto e isso tornar-se desastroso para a interpretação que depois virá. Por exemplo, no poema "O cacto", de Manuel Bandeira, pode ser desastroso se eu não compreender que "feracidade" não tem nada a ver com fera nem com atrocidade, mas com fertilidade. A leitura pode já de início desviar-se do texto correto. No poema "Áporo", de Drummond, um crítico leu, certa vez, na primeira estrofe do poema, em vez do termo "perfura", referido ao inseto que cava, "perfuma", legitimando um erro tipográfico e teve que se ver às voltas com a justificativa de sua leitura. Mas isso pode ocorrer com qualquer um que, inadvertidamente, não comece do mais simples e não leve em consideração, antes de mais nada, a precisão do sentido literal em sua correspondência com os signos corretos do poema, cujo texto deve estar perfeitamente bem estabelecido, antes que se avance no trabalho. Se não se entende um termo na acepção exata em que ele está utilizado no texto, toda construção do sentido poderá cair por terra. Esse trabalho filológico é inicialmente externo ao que de fato interessa no texto, mas pode ser decisivo como tarefa preparatória e tem a ver, desde o começo, com nossa sensibilidade para os elementos significativos. Ele não é, em princípio, uma operação interna. Mas é uma ponte para o interno. Aos poucos, quando bem conduzido, vai virando interno: os limites entre a explicação externa e a análise podem ser tênues. Nas mãos de um grande crítico, o comentário já acumula dificuldades pertinentes para serem vencidas nas etapas posteriores, que são a análise e a interpretação propriamente ditas. Essa abordagem inicial é uma preparação do terreno. Um crítico alemão que meu mestre Antonio Candido gostava de citar dizia que o comentário era o vestíbulo da boa interpretação, e continua sendo.

\section{Apostar todas as fichas no comentário torna acanhada a via interpretativa?}

Eliot afirma que é preciso saber onde parar com a explicação. Só explicar o explicável. Isso já é uma tarefa crítica. O miolo da crítica não é a explicação, mas a compreensão do que não é explicável, como sugeri faz pouco. Mas há livros de explicação utilíssimos que não chegam propriamente ao miolo da tarefa crítica e, no entanto, abrem o caminho para ela. Por exemplo, hoje, quase não podemos ler Macunaíma sem a ajuda do Roteiro de Macunaíma, de Manuel Cavalcanti Proença, esse grande estudioso de nossas letras. Isso porque é um livro preparatório do terreno. Quem pode dispensar, para o começo de conversa, o excelente livro de Stuart Gilbert ao se dispor a ler o Ulisses de Joyce?

Walter Benjamin, num texto belíssimo sobre As afinidades eletivas, de Goethe, afirma que há, na obra literária, um conteúdo de coisa e um conteúdo de verdade. No primeiro momento, os dois conteúdos estão ligados, unidos, mas conforme o tempo passa, a perspectiva histórica mostra que o factual pode boiar, como na operação de catar feijão, do nosso poeta João Cabral, enquanto o conteúdo de verdade vai para o fundo. O comentador deve limpar essa escrita do pergaminho para deixar ver o conteúdo de verdade que jaz por baixo, peneirar com jeito, para separar os grãos bons da palha e das impurezas que se acumulam, atrapalhando. Quando executa adequadamente esse procedimento, o comentador, como disse Benjamin, remove as pesadas achas do passado que recobrem o texto, para deixar a chama viva exposta à compreensão do crítico. O crítico está interessado no conteúdo de verdade, naquilo que mantém viva a chama da fogueira. Isso é tarefa da crítica literária e das operações internas. Estou falando da análise e da interpretação.

\section{Talvez valha a pena detalhar um pouco o processo analítico.}

A análise é uma desmontagem, é uma divisão do todo em partes para o reconhecimento da funcionalidade que têm as partes no todo. A interpretação é uma tradução interna, pessoal e afetiva, desses elementos que formam o todo: depende de uma reconstituição do todo, baseada na análise. A interpretação depende da constituição e da 
reorganização do todo para a tradução final dos significados num sentido. Para reforçar o que eu afirmei há pouco, gostaria de citar uma frase que está na teoria estética de Adorno: "Mesmo a obra corretamente interpretada gostaria de ser mais compreendida, como se aguardasse a palavra de resolução perante a qual se esvaeceria a sua obscuridade constitutiva". Mas isso não se cumpre de todo. Adorno considera que, mesmo quando feita corretamente, a interpretação é inesgotável. Quando ele fala disso, está tratando do caráter enigmático da obra literária e de toda obra de arte. Do simbolismo para cá, toda experiência da arte moderna frisa esse aspecto, ou seja, que a obra literária é uma espécie de enigma. A interpretação sempre lidou e lida com uma questão, no fundo, enigmática. Em inglês, enigma é uma forma de riddle, ou adivinha, que está ligada à raiz do verbo to read. Então, a leitura crítica depara no fundo com o enigma, com a pergunta da adivinha.

\section{Um de seus livros tem, justamente, o título de Enigma e comentário.}

Isso mesmo. Enigma e comentário. Quer dizer, o comentário de um enigma. Um poeta amigo meu, Antônio Carlos de Brito (Cacaso), quando eu publiquei o livro, disse: "gostei demais desse título porque todo objeto é enigma; todo pensamento, comentário". Ele estava anunciando exatamente o miolo do livro, que também é o miolo da interpretação. E a interpretação vai lidar com o caráter inexaurível do fundo da verdade literária.

O filósofo italiano Luigi Pareyson disse que a formulação da verdade é uma questão hermenêutica. Toda formulação da verdade, toda interpretação, é uma tentativa de dar conta dessa totalidade que é a verdade. Mas ela só aparece como verdade verdadeira se se mantiver como verdade infinita para a pessoa que é o intérprete. Cada um dos intérpretes deve fazer uma leitura totalizante dessa verdade: tão adequada, abrangente, coerente, que seja capaz de trazê-la viva e iluminada à nossa presença. A interpretação é total enquanto leitura pessoal da verdade. Quando o intérprete se coloca diante de uma obra de arte, ele deve saber e estar preparado para uma operação interna, afetiva e pessoal. Ou seja, a resposta interpretativa que o crítico dá ao texto não é cabal, não é nunca definitiva, como se ela exigisse sempre o movimento em aberto do ensaio: ela talvez seja lateral, sem ser unilateral, mas deve corresponder ao que a pessoa compreendeu da obra enquanto todo.

O enigma, na versão de Pareyson, é uma forma de infinito cravado no texto. Ou seja, é uma pergunta que se repete a cada passo, a cada novo leitor. O texto renova o enigma. Cada nova interpretação volta à fonte originária, que é inesgotável. Isso faz que o enigma esteja presente no miolo da obra, como um desafio à interpretação. Nessa linha de pensamento, o enigma é o lugar da pergunta. Adorno, na Teoria estética, afirma ainda que a função da crítica não é resolver o enigma, mas mostrar as razões de sua indissolubilidade.

A totalidade da verdade está inteira em cada uma das partes. E cada uma das partes remete a essa verdade total porque é uma continuidade da verdade total. Isso significa que o processo pelo qual se deve desenvolver a interpretação é uma visão da totalidade que a cada passo se justifica nas partes e se reencontra na visão do todo. O movimento da interpretação é o movimento do círculo hermenêutico de que falou Heidegger, provavelmente retomando o pensamento de Schleiermacher a esse propósito, ou seja, é um movimento do todo à parte e da parte ao todo.

O processo pelo qual eu entro no círculo é complicado. Afinal de contas, ele depende da atenção flutuante do leitor sobre o texto. Vamos colocar a seguinte situação: eliminadas as barreiras objetivas à compreensão pelo comentário, limpo o terreno, eu começo a entrada no texto. Onde me fixar? Por onde começar? Não há resposta para esse impasse inicial. Eu tenho de ler e reler diversas vezes. Devo dedicar a esta aproximação uma atenção flutuante, como talvez dissesse um psicanalista. De repente, eu me dou conta de que uma metáfora é recorrente e, portanto, tem alguma outra ligação dentro do texto. Posso perceber, também, que essa metáfora está repetida no ritmo do poema, e que o ritmo se confirma pelas rimas, 
interligando palavras-chave para a construção do sentido. Percebo assim elementos de semelhança dentro da seqüência dos signos. Portanto, na atenção flutuante dedicada ao texto é possível detectar um detalhe significativo que se liga a outros, permitindo o estabelecimento de uma cadeia coerente de significados na qual, em cada elo, está latente a totalidade. Vai-se da parte ao todo, para a cada passo, reiluminando-o, confirmar o rastilho de luz das demais partes significativas. E, à medida que se progride, vai-se criando uma imagem do todo, da mesma forma que, no começo da leitura, já se tem uma idéia obscura do todo que aos poucos vai ganhando concretude e se tornando mais nítida, mediante a interligação explicitada dos elementos particulares do texto.

\section{Um aspecto nada desprezível no processo interpretativo é a carga de experiência do} intérprete.

Aqui, há vários problemas. Toda vez que eu abordo um texto ou uma obra de arte, eu abordo com tudo o que eu sou, com toda a experiência que eu tenho acumulada (da leitura do poeta em questão, da leitura de poetas similares da época, da história da época, de todo meu conhecimento pregresso etc.), como a pessoa que sou. Eu posso dominar uma multidão de informações preciosas que me levam ao texto e interferem no entendimento dele. Essa carga de informações pode me auxiliar muito no comentário para eliminar aquilo que me impede a passagem, para o deslinde do texto, para empregar uma palavra cara ao grande escritor mexicano Alfonso Reyes, que escreveu sobre este problema palavras sábias. Por outro lado, tudo o que sei pode também se transformar numa idéia pré-concebida do texto. Eu forjo, de antemão, uma imagem projetiva do que é o texto em que esses dados prévios se incluem, determinando uma direção de leitura. Essa imagem projetiva é, rigorosamente, um pré-juízo. $\mathrm{Na}$ crítica das ciências humanas, na tarefa interpretativa, o círculo hermenêutico se abre pelo risco do preconceito, que deve de algum modo ser posto entre parêntesis para que o processo da compreensão adequada possa se dar.

Sobre isso, vale a pena relembrar a expressão suspension of disbelief, de Coleridge, ou seja, "a suspensão da descrença". Devo colocar de lado as minhas crenças, os meus conhecimentos, para poder encarar sem preconceito o texto a ser compreendido, mesmo quando ele se afasta em direções diversas ou se opõe às minhas próprias idéias e sentimentos. Devo me entregar, generosamente, a um embate direto com o texto. A falta de generosidade na leitura pode ser um empecilho lamentável da compreensão. Como dizia Heidegger, a única fonte da minha verdade é a resposta que eu possa dar à coisa em si, e não ao conhecimento prévio que eu tenha das coisas.

Para se desfazer o prejuízo, é necessário apoiar-se diretamente na coisa propriamente dita, ou seja, naquilo que está dado na estrutura significativa: aquilo que faz com que o poema seja um poema e não outra coisa. Deve-se tender a uma leitura fresca, o mais possível direta do que deve ser interpretado.

Vale a pena ressaltar o seguinte: todo o conhecimento nessa área se dá por uma antecipação do objeto, mas essa visão deve ser escorada, a todo momento, nos detalhes textuais particulares nos quais eu ao mesmo tempo confirmo minha visão e a projeto ao passo seguinte. E esse movimento de apoio confirmativo na parte só a desmontagem analítica pode dar, revelando a funcionalidade expressiva da parte na constituição do todo. A análise é um modo de objetivar a visão intuitiva do todo, confirmando-a nos detalhes que a sustentam enquanto imagem adequada da totalidade. Minha certeza de estar no caminho certo deve ser reconfirmada, por esse movimento circular, a cada passo no labirinto do sentido. Certamente a história e a linguagem são instrumentos de apoio nas vacilações do caminho.

Podemos falar um pouco de símbolos e mitos? Certamente, a partir daqui, a comparação entre interpretação literária e interpretação psicanalítica é inevitável. 
Sob muitos aspectos toda obra literária se apresenta como um símbolo e parece pedir uma decifração. Ela tende sempre a colocar uma pergunta, e não necessariamente a respondêla. A resposta à pergunta nos situaria diante do mito, que é a resposta de uma pergunta originária.

\section{O mito é o fechamento.}

Sim. O mito é a resposta. Se eu responder, eu mitifico a literatura e a transformo numa fábula moral. Os poetas não têm essa resposta. Freud, no início da psicanálise, parece utilizar a literatura como uma espécie de campo de provas da teoria psicanalítica. Vale-se dos poetas e da literatura provavelmente porque a literatura é, como o sonho, o lugar do símbolo. Mas a resposta que Freud dá a isso é, para mim, inaceitável, ou seja, a resposta do complexo de Édipo, dos desvios do desejo. Ele traduz o símbolo em mito. Todos os textos apontariam na mesma direção, mas os textos não apontam para a mesma direção. Eles recolocam a pergunta. No momento em que a interpretação psicanalítica se converte em explicação, ela se afasta da interpretação literária. E a interpretação literária deve trazer o sentido vivo, não explicá-lo.

\section{Apesar dessas ressalvas, Freud foi um leitor bastante arguto.}

Para mim, Freud é um notável crítico literário. Isso porque ele é um mestre da exegese. É um mestre da interpretação, da leitura analítica, com um senso agudíssimo do que no texto desempenha papel significativo, mas a resposta que ele por fim formula para a literatura, para o lugar da arte, me parece ainda herdeira da tradição positivista do século XIX. E isso eu não aceito. Mas é uma interpretação minha. No processo todo - não me levem a mal -, a psicanálise é um ramo da literatura, Borges disse isso da metafísica.

Toda a colocação da psicanálise se aproxima, como forma de linguagem, do desvelamento da literatura. Agora, a explicação cabal do lugar da arte, do artista, do sonho acordado análogo ao do neurótico, apenas com volta à terra, tudo isso me parece o lado mais fraco. O lado forte é justamente o processo de desvendamento do enigma. Mas, não, a solução. A solução explicativa é, para mim, o lado inaceitável da interpretação freudiana da literatura.

Mas o processo mais amplo da interpretação psicanalítica sempre me interessou e continua me interessando, porque há ali uma tentativa de decifração da linguagem simbólica, compartilhada pela literatura.

\section{A força da imaginação entra como aspecto fundamental no processo de abordagem do enigma?}

Há, certamente, a verdade da imaginação. Essa verdade da imaginação que a literatura propõe como sua verdade não é a verdade da ciência. Ou seja, a imaginação imprime um valor cognoscitivo na literatura, e isso foi percebido e dito por Aristóteles. Esse valor cognoscitivo da imaginação se refere àquilo que pode ser, não necessariamente ao que é ou foi apenas. A literatura nos propõe a cada passo algo como se fosse, e não tão somente o que é. Hipóteses de ser, que às vezes se cumprem, às vezes não. A ficção é sempre como se fosse. Personagens como D. Quixote, Falstaff, são como se fossem; são hipóteses de ser que, por vezes, nós reencontramos em nova vida, ora um pouco diluído aqui, um pouco lá. Eles existem; são criações da imaginação. É essa a força da literatura.

A força da imaginação é básica para nós. O reconhecimento do valor cognoscitivo da imaginação não escapou à percepção romântica. Antonio Candido afirma que ainda vivemos, num certo sentido, um longo pós-romantismo, porque foram os românticos que abriram a 
possibilidade de a gente apreender o valor da imaginação como uma forma de conhecimento. Podemos dizer que a imaginação é a força plasmadora de tudo que tem valor em arte, da forma artística como tal.

Na interpretação literária não há como fugir do seguinte ponto: as múltiplas possibilidades oferecidas pelo texto literário. Sobre isso, um equívoco freqüente é a busca da resposta definitiva.

$\mathrm{Na}$ verdade, uma teoria da interpretação é uma teoria das relações entre a imagem e o sentido. É uma teoria do símbolo, do duplo sentido, do signo que não se limita a designar um sentido primeiro, mas dá acesso a um sentido segundo através do primeiro. Isso é a literatura e o que faz com a linguagem. Cria um mundo como se fosse e que às vezes se encarna na história. Às vezes não. Por isso, Aristóteles dizia que a literatura é mais filosófica do que a história, porque a história só cuida do que foi. E a literatura cuida do que pode ser. O poder ser é o lugar da imaginação. É isso que faz, por exemplo, Jorge Luís Borges, esse grande escritor, dizer que o estético é o lugar do enigma, porque se situa no limiar de uma revelação que, no entanto, não se produz. O estético é um lugar de uma revelação que não se cumpre. É a iminência da revelação, ou seja, é aquilo que pode ser.

Borges, por exemplo, enfrenta um problema da história literária, o falso problema de Ugolino, que é uma passagem famosa do canto 33 do Inferno de Dante. Trata-se da história de um conde pisano, Ugolino della Gherardesca, que foi encerrado com seus dois filhos e dois netos numa torre, depois conhecida como a Torre da Fome, acusado por um arcebispo, Ruggero, de ter traído a cidade de Pisa, entregando territórios dela a outras cidades italianas com as quais estava em luta. Na abertura do canto 33, Dante e Virgílio chegam à prisão, e Ugolino está roendo o crânio do arcebispo que o denunciou e, depois de limpar a boca na cabeleira de Ruggero, narra a história terrível de seu fim. Aí ele limpa a boca nos cabelos do sujeito que está sendo comido e diz a Dante: "Pretendes que eu renove, inteira, a dor que ainda me punge o peito e a mente [...] relatando aquilo que aconteceu comigo?". Então, ele conta que foi encerrado naquela torre e, depois de ver várias vezes a lua erguida no céu, teve um sonho: sonhou que era um lobo com seus filhotes acuado por uma matilha de cães de caça do arcebispo e de seus comparsas que o perseguiam até a exaustão, de modo que um cão já lhes metia os dentes. Naquele desespero, na angústia daquele sonho, ele mal desperto ainda, com o clarão do dia, julga ouvir os soluços dos filhos implorando pão. Logo, ouve o batimento dos pregos que estavam encerrando-os na prisão. Percebe que seu destino está selado e que está posto ali para morrer de fome com seus descendentes. O seu desespero vai crescendo, enquanto vê crescendo a fome entre as crianças. Ele morde a mão, em dor desatinada. E um dos filhos lhe oferece a própria carne, julgando que fosse por fome que mordia, e dessa forma essa carne à sua origem voltaria. Numa certa altura, no verso 75 do canto 33, vem então o seguinte verso: Pascia, piú che'l dolor pote'l digiuno [Depois, mais que a dor pôde o jejum]. Todos os comentadores antigos do texto entenderam que ele morreu simplesmente, morreu de fome, tendo esta necessidade superado a trágica dor. Mais que a dor, o jejum decidiu o destino de todos, matando-os. Os modernos levantaram a hipótese de que, nesse verso, haveria uma sugestão de canibalismo, que Ugolino teria devorado os filhos. Desesperado, teria comido a carne que ele próprio gerou. Há vários índices: o lobo perseguido a dentadas, a carne do filho oferecida ao pai. Há outros detalhes, ainda, que reforçam o mesmo sentido, sugerindo essa interpretação. Ugolino comeu ou não seus descendentes? É um problema? Borges afirma, a meu ver, com inteira razão, que é um falso problema. Ugolino comeu e não comeu. Pode ter comido, o que é mais terrível que comer. A literatura está na iminência de uma revelação, não na revelação.

Talvez se possa dizer algo parecido do enigma de Capitu. Capitu traiu ou não traiu? Pode ter traído. Essa é a resposta, a resposta da ambigüidade. Essa resposta preserva a leitura 
de Dom Casmurro e vai fazer, em todo o tempo, metade da crítica dizer que traiu e metade dizer que não traiu. Mas a crítica, a meu ver, que melhor acerta o alvo será a que diga: traiu e não traiu. Pode ter traído. Porque o símbolo é a potencialidade do ser, não o fato acontecido. Essa experiência é fundamental para que o estético se mantenha. A tradução em outra coisa liquida a possibilidade da interpretação simbólica da literatura. A duplicidade é a característica fundamental do símbolo.

Como Marx, Freud desconfiava sempre do que está por baixo. Agora, para a literatura, a explicação cabal do que está por baixo pode ser desastrosa se você revelar tudo. Não existe a interpretação completa. Não existe interpretação definitiva, porque o enigma é inesgotável.

Um bom exemplo dessa inesgotabilidade do enigma poderiam ser as imagens do "áporo" e da "salamandra", tal como aparecem nos poemas famosos de Carlos Drummond de Andrade, que eu analisei em detalhe em dois capítulos de meu livro: Coração partido. Uma análise da poesia reflexiva de Drummond. Na verdade, o "claro enigma" é a fonte perene de que brota a admirável lírica meditativa do grande poeta.

Normalmente, a poesia é definida como a mais poderosa das manifestações literárias. Você poderia dar algumas explicações sobre a força da poesia?

A poesia é uma forma de condensação. É uma síntese da totalidade. Isso é a coisa mais bonita no poema. O poema se cumpre em poucas palavras. É próprio do lírico cumprir-se na brevidade. Mas ao cumprir-se na brevidade, ele é capaz de dar conta do universo, de condensar o mistério do universo. A poesia é a linguagem mais condensada, mais prenhe de significados que o homem inventou.

A condensação é um dos modos de exprimir a capacidade do símbolo de encerrar significados múltiplos num único signo. Todos os recursos estão postos para fazer a palavra vibrar nos mais diferentes planos e condensar o máximo de carga de sentido que ela possa ter. Por isso mesmo, a prosa, quando é alta prosa, se faz poesia pela força de condensação que adquire. Mas a poesia é onde mais se pode observar essa força extraordinária de uma emoção que sintetiza o universo em palavras.

Paul Valéry, que sempre foi muito atento a isso, chamou a atenção para o fato de que a emoção poética se distingue da emoção banal - do medo, da coragem, do amor, enfim de todas as emoções -, porque, na verdade, é uma emoção que nos dá a sensação de universo. Ou seja, ela tem a capacidade de - esse verbo talvez não exista, mas se pode formar - constelizar, fazer constelação de coisas que não estão ligadas. Por isso o enlace de coisas heterogêneas na imagem é tão poético, porque quando se aproximam coisas que aparentemente não tinham relação alguma para a percepção corriqueira, a gente tende a avaliar essas coisas como semelhantes de algum modo. Ou reconhecer e reavaliar os limites e as diferenças entre essas coisas.

Na poesia, toda sequiência é analógica, funda semelhanças. Tudo o que está perto a gente tende a avaliar como próximo no plano dos significados; somos assim levados a perceber, com surpresa imaginativa, a semelhança de seres díspares. O ritmo e a repetição são procedimentos de que a poesia se serve para tornar a sequiência representativa da semelhança, constelizando elementos heterogêneos na mesma corrente de emoção que os interliga e tensiona, formando um todo significativo. O universo, múltiplo e caótico, tende a se unificar na poesia.

\section{Como você articularia literatura e desejo?}

$\mathrm{Na}$ narrativa literária, todo movimento é a história do desejo que topa com dificuldades para ir a seu objeto. Ou seja, todo o percurso do desejo para se cumprir é o objeto da narrativa. A narrativa vive das contradições que sofre o desejo e da falta que isso traz, por 
não se cumprir. Esse movimento é o movimento da narrativa. $\mathrm{O}$ diabo é o elemento contraditório e de divisão que estimula o movimento da narração; é aquilo que impede que o desejo se cumpra e nos força a narrar. Quando o desejo se cumpre, a narrativa acaba. É preciso que haja sempre a contraparte do diabo que acende o desejo. O desejo, como Montaigne dizia, cresce com a dificuldade. A história da narrativa é uma história dessas dificuldades.

\section{A poesia também trabalha com isso?}

A poesia também diz isso, de algum modo, e diz nos extremos. Na origem da lírica está o ditirambo, que é a expressão da mais profunda alegria e da tristeza mais profunda. Essa oscilação é a oscilação máxima da lírica. A origem da lírica é o oráculo, a expressão lapidar do oráculo. A palavra lírica é uma forma de sentença oracular. Por isso, ela é imagem enigmática. A narrativa apenas desdobra as imagens oraculares no movimento do ritual, que está na origem da narração. Essas imagens são desdobradas no movimento narrativo e são sintetizadas no instantâneo lírico.

Em determinado momento da nossa conversa, você delimitou os terrenos da interpretação literária e da interpretação psicanalítica. Ainda assim, é possível ver algum tipo de influência da psicanálise sobre a literatura?

A psicanálise sempre teve, desde o início, contato estreito com a literatura, pois, como se sabe e ficou dito aqui, Freud se serviu da literatura como campo de provas da psicanálise. Jean Starobinski, um crítico suíço de grande importância, tem um ensaio excelente, em $L a$ relation critique, que trata da relação da literatura com a psicanálise, debruçando-se sobretudo nos elementos em que a psicanálise, no curso de sua elaboração, tomou emprestado da literatura para assimilá-los à sua própria estrutura doutrinária. Eu sempre tratava desse ensaio com meus alunos, porque nele estavam discutidas as diferenças na concepção final da interpretação no terreno literário e no terreno da psicanálise, mas também a aproximação íntima pela qual a psicanálise, devolvendo os materiais de empréstimo, acaba falando a mesma linguagem da literatura.

A psicanálise impregnou toda a tradição da crítica literária do século XX. Num grande crítico da estilística, que já citei aqui, Leo Spitzer, ela se incorporou profundamente na sua concepção mesma da linguagem literária e do estilo como desvio lingüístico, até na noção que no início desenvolveu do etymon espiritual de um autor, como concepção da unidade profunda de sua obra. Nos Estados Unidos, Kenneth Burke, por exemplo, tentou juntar marxismo com psicanálise na crítica, na análise dos motivos, na gramática dos motivos. A psicanálise entrou profunda, mas indiretamente, em alguns críticos, em Richard Blackmur, por exemplo, que era um leitor fenomenal de poesia e de intrincados labirintos de certos prosadores, como Henry James. A psicanálise também está presente em William Empson, que escreveu aquele livro Sete tipos de ambigüidade, muito próximo das latências da psicanálise, sem falar nos que beberam diretamente na doutrina psicanalítica como Charles Mauron, na França, ou Maud Bodkin, nos Estados Unidos. Alguns críticos desenvolveram conceitos apoiados na psicologia profunda de Jung, como Gaston Bachelard e sua fenomelogia da imaginação, centrada na teoria do devaneio a partir dos elementos materiais do universo: o fogo, o ar, a água e a terra. Mais indiretamente, percebe-se, nessa mesma direção, o aproveitamento de tipos de Jung, na visão do romanesco tal qual a concebeu o grande teórico e crítico canadense Northrop Frye. No Brasil, poderíamos começar por Mário de Andrade, que acompanhou de perto o desenvolvimento da psicanálise e fundou nela muitas de suas idéias críticas, antes que a psicanálise penetrasse largamente na crítica universitária, depois dos anos de 1940, até o presente, como se vê em vários de meus colegas de ofício. Por tudo 
isso, e muito mais, que não há tempo para desenvolver, é impossível não levar em conta a psicanálise se se quer compreender o que se passou nas diversas correntes da crítica literária do século XX, em que se manifesta direta ou indiretamente sua marcante presença, tanto nas concepções da psicologia do criador ou da gênese da obra, até como instrumento de trabalho na análise dos fantasmas do desejo que assombram as obras literárias. 